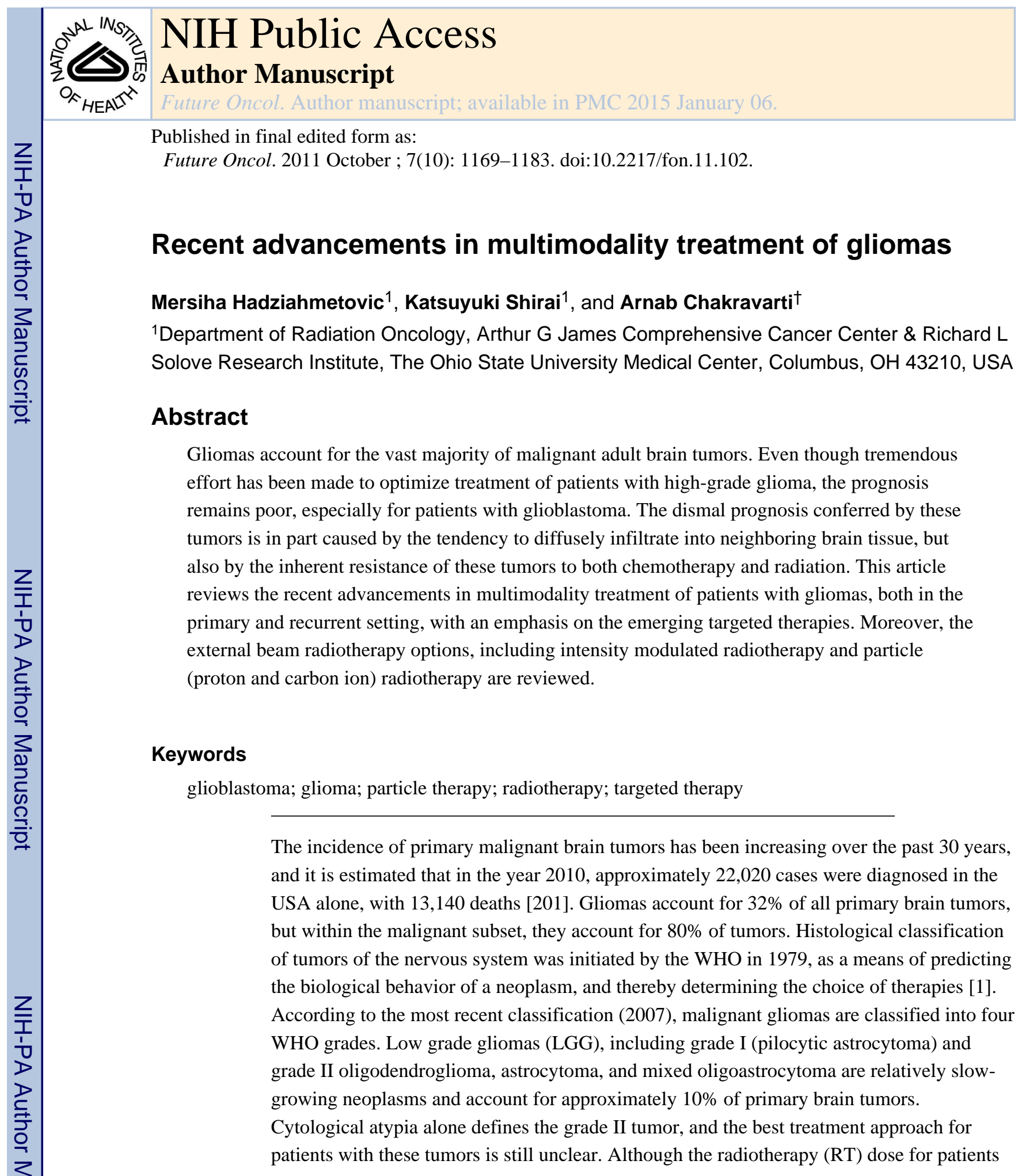

(C) 2011 Future Medicine Ltd

${ }^{\dagger}$ Author for correspondence: Department of Radiation Oncology \& Max Morehouse Chair of Cancer Research, The Ohio State University Comprehensive Cancer Center, The James Cancer Hospital \& Solove Research Institute, The Ohio State University College of Medicine, Columbus, OH 43210, USA $\boldsymbol{\square}$ Tel.: +1 6142930672 a Fax: +1 6142931943 arnab.chakravarti@osumc.edu.

Financial \& competing interests disclosure The authors have no relevant affiliations or financial involvement with any organization or entity with a financial interest in or financial conflict with the subject matter or materials discussed in the manuscript. This includes employment, consultancies, honoraria, stock ownership or options, expert testimony, grants or patents received or pending, or royalties.

No writing assistance was utilized in the production of this manuscript. 
with a grade II tumor is well-established, the timing of RT, precisely early versus delayed, remains contentious owing to the fact that potential toxicity must be balanced against the long natural survival.

High grade gliomas (HGG), including grade III anaplastic astrocytoma (AA), anaplastic oligodendroglioma (AO), anaplastic mixed oligoastrocytoma (MOA) and grade IV glioblastoma (GBM), account for approximately $60-75 \%$ of all gliomas. Histologically, tumors showing anaplasia and mitotic activity are classified as grade III, while the sine qua non of grade IV tumors is microvascular proliferation and/or necrosis. Historically, all HGG have been treated in the same manner, but the treatment modality for grade III tumors is currently being investigated separate of grade IV tumors through ongoing clinical trials. The average survival time of approximately 1 year for patients with glioblastoma (GBM) has minimally improved despite decades of basic and clinical research. However, in recent years a significant survival benefit has been achieved with the addition of concurrent temozolomide (TMZ) to adjuvant RT.

The dismal prognosis of GBM patients is in part caused by the resistance of these tumors to both chemotherapy and radiation, as most tumors recur within the irradiated portals. Poorly understood mechanisms of tumor resistance and migration account for such a high rate of recurrence and progression. Identifying the best treatment for each grade and molecular subtype of gliomas will help guide physicians in providing more effective therapies for patients. The current trends in cancer research aim to identify novel molecular targets for each glioma grade, and thereby enhance the therapeutic ratio of conventional and experimental therapeutics.

From the RT standpoint, the quest for optimizing local control of gliomas with external photon beam RT has evolved from the classic opposed lateral fields encompassing the whole brain to the highly conformal intensity modulated RT (IMRT). Other radiation modalities, such as particle RT, are also being investigated. In addition to reviewing the standard of care for different grade gliomas, we will also review the evolution of targeted therapy, as well as technological advances in neuroimaging and RT as part of treatment for these tumors.

\section{Low grade gliomas}

Low grade gliomas tend to exhibit a heterogeneous clinical behavior, and patients may survive from less than a year to 20 years or more after initial diagnosis [2]. In general, they are relatively slow-growing primary malignant brain tumors and majority are capable of undergoing higher-grade transformation. Standard treatment consists of surgical debulking whenever possible, so as to decrease the risk or recurrence and transformation to higher grade [3]. However, many aspects of treatment are controversial, namely timing and aggressiveness of surgery, as well as timing of RT and whether there is a role for chemotherapy. Controversy stems from the need to reconcile the risk of potential toxicities of aforementioned treatments in the relatively younger patient cohort, owing to the fact that LGGs have a long natural history. For older patients, the standard remains to proceed with immediate postoperative radiation. European Organization for Research and Treatment of Cancer (EORTC) and Medical Research Council (MRC) conducted a clinical trial wherein 
311 patients with LGG were randomized after surgery to receive adjuvant radiation (54 Gy in 30 fractions) versus no adjuvant therapy until tumor progression, as defined by neurologic deterioration and/or radiologic progression [4]. After a median follow-up of 7.8 years, the irradiated group demonstrated a significant improvement in time to progression (TTP 5.3 vs 3.4 years, $\mathrm{p}<0.0001$ ), but not in median overall survival (mOS 7.4 vs 7.2 years). Of note, seizures were better controlled in the early RT group [5].

In general, patient presentation tends to dictate the initial course of treatment. Using distinct datasets from the EORTC trials with adult patients with LGG, Pignatti and colleagues have identified prognostic factors for survival in patients with LGG and derived a prognostic scoring system to help guide timing and aggressiveness of initial therapy [6]. Multivariate analysis identified the following five prognostic factors:

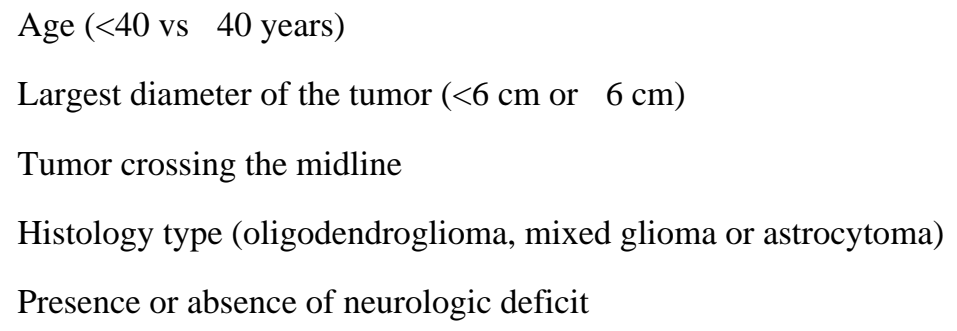

The effect of each factor was considered to be one, and patients with two or fewer risk factors (i.e., low risk) were found to have an expected median survival of $\geq 7$ years, whereas patients having three or more risk factors (i.e., high risk) have a significantly shorter median survival time. In the latter group, RT is recommended early or upfront after surgery, whereas in low-risk patients it is usually delayed until radiologic or symptomatic progression.

The North Central Cancer Treatment Group (NCCTG), Eastern Cooperative Oncology Group (ECOG) and the Radiation Therapy Oncology Group (RTOG) conducted a Phase III prospective randomized clinical trial of low versus high dose (50.4 Gy vs $64.8 \mathrm{~Gy}$, delivered in $1.8 \mathrm{~Gy}$ fractions) RT in adults with supratentorial LGG, and after a median follow-up of 6 years, the 5 year disease-free survival (DFS) and OS were the same. The 2 year actuarial incidence of grade 3-5 radiation necrosis was double with the high-dose RT, 2.5 versus 5\% [7]. Similarly, EORTC conducted a radiotherapeutic dose-response trial comparing adjuvant doses of 45 Gy versus 59.4 Gy in patients with LGG, and found no significant difference in terms of survival (58\% for the low dose arm and 59\% for the high-dose arm), nor the progression free survival (PFS 47 vs 50\%) between the two arms of the trial [8].

Initial reports of effectiveness of chemotherapy in grade II glial tumors typically used the procarbazine, lomustine and vincristine (PCV) regimen, and more recently the effectiveness of adjuvant monotherapy with TMZ, an oral alkylating agent, has been tested in a trial setting, with reported response rates of 20-52\% [9,10]. Results of the RTOG 9802 trial have been reported in abstract form and show that addition of PCV chemotherapy to adjuvant radiation in patients $\geq 40$ years with suboptimal resection conferred a survival advantage beyond 2 years [11]. 


\section{High grade gliomas}

Historically, surgery followed by RT remained the gold standard treatment for HGG, but it conferred a dismal prognosis with an estimated 5 year OS of 2-3\% [12]. Nevertheless, the effectiveness of postoperative radiation was so convincing in the early trials by the Brain Tumor Cooperative Group, that all subsequent trials of adjuvant therapy included radiation in all treatment arms. The efficacy of chemotherapy was more difficult to demonstrate, but most patients with HGG received additional carmustine or a combination regimen comprised of PCV [13]. However, the most recent paradigm shift in treatment of HGGs occurred with the EORTC Phase III study that demonstrated a significant survival benefit in patients with GBM with the addition of concurrent and adjuvant TMZ to radiation [14]. TMZ is a monofunctional alkylating agent, and has advantages such as ease of administration (per os), favorable toxicity profile, and the ability to cross the blood-brain barrier. In this landmark study by Stupp and colleagues, 573 patients with newly-diagnosed GBM (84\% of which were surgically debulked) were randomized to receive RT alone (60 Gy in 30 fractions) or RT plus continuous daily TMZ $\left(75 \mathrm{mg} / \mathrm{m}^{2}\right.$ body surface area from the first to the last day of RT), followed by six cycles of adjuvant TMZ (150-200 mg/m² body surface area for 5 days during each 28-day cycle) [14]. At a median follow-up of 28 months, the median survival was 14.6 months with RT plus TMZ versus 12.1 months with RT alone, rendering the hazard ratio for death 0.63 in the combined modality group. Moreover, the 2 year OS was $26.5 \%$ with RT and TMZ and $10.4 \%$ with RT alone. In this trial, patients whose tumor had a methylated methylguanine methyltransferase (MGMT) gene promoter had improved survival (mOS 21.7 vs 12.7 months, OS at 2 years 46 vs 13.8\%) relative to those with an unmethylated $M G M T$ promoter, and the methylation status was the strongest predictor for outcome and benefit from TMZ chemotherapy [15]. A 5-year analysis demonstrated that OS was $9.8 \%$ with RT and TMZ, versus $1.9 \%$ with RT alone [16]. Optimizing the adjuvant chemotherapy regimen is now one potential strategy to improve patient outcomes, specifically in patients with unmethylated $M G M T$ promoter. A randomized Phase II trial that compared six cycles of adjuvant dose-dense $\left(150 \mathrm{mg} / \mathrm{m}^{2}\right.$ days 1-7 and 15-21) or metronomic ( $50 \mathrm{mg} / \mathrm{m}^{2}$ continuous daily) TMZ demonstrated that the former approach conferred a 1 year survival of $80 \%$, median survival 17.1 months and PFS at 6 months of $56 \%$ [17].

Until recently, all HGGs have been treated in the same manner, but the treatment modality for AA, AO or anaplastic MOA tumors is currently being investigated separate of grade IV tumors through ongoing clinical trials. Accrual has completed for RTOG 9813, a Phase III randomized study of RT and TMZ versus RT and nitrosourea for AA and astrocytomadominant anaplastic MOA, and results are awaited.

Interest in the use of chemotherapy for patients with oligodendroglial or mixed gliomas was driven by the discovery that a subset of these patients exemplified remarkable chemosensitivity to the combination of PCV chemotherapy. EORTC conducted a randomized trial wherein 368 patients with $\mathrm{AO}$ or anaplastic MOA underwent resection and adjuvant RT alone with or without PCV chemotherapy. The 5-year analysis demonstrated that the addition of PCV chemotherapy improves PFS (RT + PCV 1.9 vs RT 1.1 years), but not OS (3.4 vs 2.6 years) in these patients [18]. Cairncross and colleagues demonstrated that 
alterations of the chromosome arms $1 \mathrm{p}$ and $19 \mathrm{q}$, in particular the loss of heterozygosity, confer chemotherapeutic sensitivity and prolong OS in grade III (anaplastic) AO treated with PCV $[19,20]$. In a series of 162 patients with pure or mixed glioma, Smith et al. demonstrated that the combined loss (deletion) of $1 \mathrm{p}$ and $19 \mathrm{q}$ is a statistically significant predictor of prolonged survival in patients with pure AO, independent of tumor grade [21]. No such association was demonstrated in patients with astrocytic neoplasms. All patients with the codeletion were alive after a median follow-up of 67.5 months, as opposed to $73 \%$ of those without the combined deletion. In this study, loss of $1 \mathrm{p}$ or $19 \mathrm{q}$, in isolation, was not a significant predictor of OS in any of the subtypes examined, but patients with pure AO did demonstrate a trend $(\mathrm{p}=0.15)$ toward better survival if their tumors exhibited loss of $1 \mathrm{p}$ or $19 \mathrm{q}$.

In another series, 50 patients with AO were treated with a chemotherapeutic regimen (PCV in 48 patients) as the main initial adjuvant therapy, and patients with combined deletion of $1 \mathrm{p}$ and $19 \mathrm{q}$ had marked and durable responses to chemotherapy associated with long survival, with or without postoperative RT [22]. Patients with chromosome 1p alterations also responded superiorly to chemotherapy, but had shorter duration of response and survival. Tumors lacking $1 \mathrm{p}$ loss, but having a TP53 gene mutation, responded to chemotherapy but recurred quickly. The group that fared the worst included tumors with intact $1 \mathrm{p}$ and wild-type TP53; these were poorly responsive, aggressive tumors that were clinically similar to GBMs. Within the subset of patients with AO who have the $1 \mathrm{p} / 19 \mathrm{q}$ codeletion, those with polysomy of chromosomes 1 and 19 were found to have an earlier recurrence than those without polysomy [23].

Owing to a more favorable toxicity profile of TMZ compared with PCV, RTOG conducted a Phase II trial of preirradiation and concurrent TMZ in patients with newly diagnosed AO and mixed glioma. The objective response rate was 58\% (32\% complete response), and rate of progression during the pre-RT TMZ was only $10 \%$, as compared with $20 \%$ in historical control with PCV [24]. All patients with codeletion of 1p/19q and/or MGMT-promoter methylation were free from progression at 6 months. Whether a chemotherapy-only regimen is sufficient to provide long-term control of $1 \mathrm{p} / 19 \mathrm{q}$ codeleted $\mathrm{AO}$ or MOA without the use of concurrent or separate RT remains to be determined. EORTC is currently conducting CATNON, a Phase III intergroup trial on concurrent and adjuvant TMZ chemotherapy in patients with non-1p/19q deleted anaplastic glioma. The objectives of this trial are to assess whether concurrent RT with daily TMZ improves OS as compared with no daily TMZ in this patient population, and whether adjuvant TMZ improves OS as compared with no adjuvant TMZ. In addition, an intergroup trial by RTOG, EORTC and NCCTG is conducting the CODEL trial, wherein patients with $1 \mathrm{p} / 19 \mathrm{q}$ codeleted WHO Grade III malignant gliomas will be randomized to one of three arms following maximum safe resection: RT, primary TMZ or RT and TMZ.

\section{Targeted therapy in HGG}

Recent discoveries in the field of molecular biology have identified several signaling pathways that are involved in the development of malignant behavior, as well as treatment resistance, of malignant gliomas. A better understanding of these molecular pathways has 
allowed for development of so-called targeted therapy, which is considered an attractive therapeutic strategy to improve the prognosis of patients with HGG. One example of targeted therapy is EGFR tyrosine kinase inhibitors (TKI). EGFR overexpression has been demonstrated in malignant gliomas, and is associated with antiapoptotic tendency conferred by activated signaling pathways, tumor survival, and proliferation. Gefitinib and erlotinib are examples of EGFR TKIs that inactivate the downstream signaling pathways, and have been tested in the recurrent GBM setting [25]. However, clinical studies utilizing EGFR inhibitor monotherapy have shown disappointing results for recurrent GBM [26,27]. However, when used in combination with ionizing radiation the EGFR inhibitors have been shown to augment the antiproliferative and proapoptotic activity by ionizing radiation in several human cancer cell lines, as well as in mice bearing human colon cancer xenografts, as demonstrated by Bianco and colleagues [28].

RTOG conducted a Phase I/II study (0211) utilizing gefitinib with RT in patients with newly diagnosed GBM, and compared with historical studies, the combined therapy did not improve survival [29]. Prados and colleagues performed a Phase II study of combining erlotinib with RT and TMZ in patients with newly-diagnosed GBM, and demonstrated a 5 month improvement in the median survival with this approach (19.3 months vs 14.1 months in the combined historical control studies) [30]. In this study, a strong positive correlation between $M G M T$ promoter methylation and survival was redemonstrated. However, other studies utilizing a similar approach of combined targeted and conventional therapy demonstrated inferior outcomes and high treatment-related toxicity and death rate [31,32]. The efficacy of EGFR inhibitors remains controversial for newly diagnosed GBM, although some patients have been reported to respond dramatically to EGFR inhibitor. To reconcile the disparity between EGFR overexpression in GBMs (up to 50\% tumors) with only 10$20 \%$ of GBM patients that have a response to EGFR TKIs, biological markers to predict treatment response have been reported. Markers such as EGFR variant III (EGFRvIII), phosphatase and tensin homolog (PTEN) expression, and phospho-Akt (P-Akt), have been reported to predict the treatment response and can potentially be used to identify the patients that will derive survival benefit from the addition of EGFR inhibitor [33]. Specifically, coexpression of EGFRvIII and the tumor-suppressor protein PTEN was associated with a significant clinical response to EGFR TKI. Further studies are needed to discern the right type of patient with primary malignant brain tumor for EGFR inhibitor therapy, and how to optimize the therapeutic ratio with these agents in general. However, at least one other study did not corroborate the finding that the presence of EGFRvIII and intact PTEN predicts response to therapy with EGFR inhibitors [34,35].

In a recent Phase II multicenter trial of EGFRvIII-targeted vaccination in 18 patients with GBM who received the standard therapy of gross total resection followed by RT and concurrent TMZ, the 6 month PFS after vaccination was 67\%, and median OS was 26 months [36]. The development of specific antibody or delayed-type hypersensitivity to EGFRvIII had a significant effect on OS. When these patients recurred, $82 \%$ had lost EGFRvIII expression.

Another class of targeted therapy includes antiangiogenic agents [37]. GBM has long been recognized as a highly angiogenic tumor. Bevacizumab, a humanized monoclonal antibody 
that recognizes and blocks VEGF, was recently approved by the US FDA as a second-line or salvage treatment of GBM. Recent studies of recurrent GBM have shown that bevacizumab improved response rate and PFS, but specific adverse effects have also been reported, such as intracranial hemorrhage, gastrointestinal perforation, and thromboembolic complications $[38,39]$. To evaluate its effect in the upfront setting, Lai et al. conducted a Phase II study of bevacizumab and TMZ during and after RT for patients with newly diagnosed GBM [40]. They reported a median OS and PFS of 19.6 and 13.6 months, respectively. The authors concluded that the addition of bevacizumab improved progression-free survival, but not OS, compared with the historical studies. Currently, RTOG is conducting a Phase III doubleblind placebo-controlled trial of conventional concurrent chemoradiation and adjuvant TMZ plus bevacizumab versus conventional concurrent chemoradiation and adjuvant TMZ in patients with newly diagnosed GBM. Results are impatiently awaited, as this study will determine the efficacy of adding bevacizumab to standard treatment.

Cilengitide, one of the other antiangiogenic drugs, inhibits av $\beta 3$ and avp $\beta 5$ integrin receptors, resulting in apoptosis of GBM cells [41]. Cilengitide monotherapy for recurrent GBM has a modest effect and confers an approximate 6 month PFS of 15\% [42]. Currently, Stupp and colleagues are conducting randomized studies of RT plus TMZ with or without cilengitide for newly diagnosed GBM, after showing in a Phase I/IIa study that addition of concomitant and adjuvant cilengitide to standard chemoradiotherapy demonstrated promising activity in patients with GBM with MGMT promoter methylation [43]. Initial results have been reported in abstract form and revealed a PFS at 6 months of $69 \%$, PFS at 12 months $33 \%$, and median PFS of 8 months. The OS at 12 months was $68 \%$, and $35 \%$ at 24 months. In this trial, as well, both PFS (13.4 vs 3.4 months) and OS (23.2 months vs 13.1 months) were improved if $M G M T$ promoter was methylated.

Multiple other targeted therapies combined with RT and TMZ have also been reported for malignant glioma, albeit most of them in the recurrent disease setting (Table 1). Targets include growth factor ligands, receptors, intracellular downstream effectors, as well as multitargeted kinase inhibitors (Table 1). Unfortunately, most of the reported results are not very encouraging. One of many targeted agents that have been tested is talampanel, a noncompetitive antagonist of the a-amino-3-hydroxy-5-methyl-4-isoxazole-propionic acid (AMPA) receptor, which may inhibit invasion and growth of GBM [44]. In a multicenter Phase II trial of talampanel in addition to RT and TMZ for newly diagnosed GBM, median survival of 20.3 months and a 2 year OS of $41.7 \%$ was achieved. Of note, only $29 \%$ of patients in this series had MGMT promoter methylated, as compared with $43 \%$ in the EORTC study by Stupp [45]. Another agent that has been tested is bortezomib, a proteasome inhibitor that can arrest cell growth and induce apoptosis in GBM cells [46]. Phase I study of bortezomib with RT and TMZ in patients with primary and recurrent malignant gliomas demonstrated a median survival time of 15 months without severe toxicity [47].

These novel targeting therapies add to our armamentarium and enable us to devise a more effective treatment strategy by tackling the underpinnings of radioresistance of malignant gliomas. Although most studies are Phase I or II, with a relatively short follow-up time, 
several of these agents warrant testing in a larger and randomized setting to truly discern their efficacy and safety, with the overarching hope of improving our patients' prognosis.

\section{Imaging}

Imaging of gliomas is of paramount importance for tumor delineation and design of local treatment (i.e., RT). LGGs show intact blood-brain barrier and typically lack contrast enhancement on computed tomography and MRI, thereby rendering them poorly demarcated and a challenge when it comes to tumor delineation [48]. PET has been used to assess cerebral metabolism of patients with gliomas, but the 18F-2-fluoro-2-deoxy-D-glucose (FDG) tracer has not been accepted as a tracer of choice for patients with brain tumors, because of the high uptake by normal gray matter, thereby limiting the tumor recognition capacity. Taking advantage of tumor cells' increased expression of amino acid transporters, radiolabeled amino acid tracers have demonstrated increased sensitivity and specificity as compared with computed tomography, MRI and FDG-PET in diagnosis of glial brain tumors. L-methyl-(11C)methionine (MET) tracer has been shown to have a relatively low uptake by brain parenchyma, but high uptake of the amino acid tracer by tumor cells. Owing to this, MET-PET has largely supplanted the FDG-PET in assessing the extent of glial tumors of all grades [49]. Moreover, it can be used to differentiate between recurrent brain tumors and radiation necrosis, as well as to aid in target delineation in RT planning [50]. However, owing to the short physical half-life (20 min) of carbon-11, on-site cyclotron is necessary for MET-PET examinations. To obviate this need, another amino acid tracer with comparable quality to MET-PET is O-(2-(18F)fluoroethyl)-L-tyrosine (18F-FET) tracer, with a half-life 110 mins. It is increasingly used in a diagnostic and treatment planning $\mathrm{c}$ apacity [51].

\section{Intensity modulated radiation therapy}

Radiotherapy has improved several clinical end points in brain tumors, including OS in GBM and PFS in LGG [52]. For decades, it has remained the standard adjuvant treatment for HGGs, and is the primary treatment modality for unresectable HGGs. However, RT can also substantially contribute to late tissue toxicities such as radionecrosis and neurocognitive dys-function, as per dose-volume relationship that dictates the risk of toxicity. Therefore, the therapeutic challenge in the use of external beam RT for brain tumors is establishing a balance between tumor control and the normal tissue tolerance. Given that most recurrences are local and that the outcome with partial brain RT is not inferior in terms of tumor control or OS, the field arrangement for gliomas has evolved from opposed lateral fields encompassing the whole brain to conformal RT, and has now culminated with IMRT. With the advent of computed tomography, 3D conformal RT (3DCRT) has become widespread in its use for nearly all treatment sites, including brain, because of its advantages in improving conformity of dose around the target. IMRT is one form of 3DCRT that is optimized to protect adjacent normal tissues from high doses of radiation while still delivering adequate doses to the target volume. Although conventional 3DCRT can achieve similar results, the dose fall-off at the edge of the treatment volume with IMRT can be much more pronounced when compared with that of conventional 3DCRT, which is important especially when the treatment volume abuts an important structure. In the brain, achieving dose reductions in the 
normal tissues such as brain stem and optic apparatus translates into more favorable toxicity profile. The basis of IMRT is the inverse-planning system, which optimizes delivery of nonuniform beam fluences from multiple directions, and involves the use of multileaf collimators that divide each beam into many small beamlets of varying intensity [53]. In terms of local control afforded by IMRT for gliomas, it is comparable to that of conventional 3DCRT. Theoretical concern with the use of IMRT is that it can increase the normal tissue integral dose (NTID), which is the volume integral of the dose deposited in a patient. This is said to be owing to larger number of monitor units used in IMRT, and the concern is that the volume of normal brain exposed to any dose of radiation can increase the risk of secondary brain tumors [54]. To minimize this risk, it has been demonstrated that NTID is a function of beam energy and number of beams, and with four to eight or more beams, the variation in NTID is $\leq \%$ [55].

\section{Reirradiation of patients with glioma}

Local recurrence remains the most common form of relapse in patients with HGG [34]. Currently, the salvage options include resection, systemic agents and reirradiation. Increasingly, stereotactic radiosurgery (SRS) and (hypo)fractionated stereotactic RT (SRT) are being used in patients with recurrent HGG, especially if surgical extirpation is not an option. Both approaches utilize modern, sophisticated RT modalities that allow for delivery of very conformal high dose radiation. Fogh and colleagues have reported the largest series to examine the efficacy and tolerability of hypofractionated SRT (H-SRT). They treated 147 patients with recurrent HGG who were treated with a median dose of $35 \mathrm{~Gy}$ in $3.5 \mathrm{~Gy}$ fractions [56]. In this series, H-SRT was administered independent of reoperation or concomitant chemotherapy. This treatment was well tolerated and resulted in a median survival time of 11 months. In another relatively large series, 101 patients with recurrent HGG were treated with fractionated SRT to a median dose of $36 \mathrm{~Gy}$ in $2 \mathrm{~Gy}$ fractions $(5 \times 2$ Gy per week) [57]. Treatment was well-tolerated and effective, with a median survival after reirradiation of 8 months for patients with GBM, and 16 months for patients with WHO grade III tumors. The same median survival time was reported by the same group for patients who received reirradiation with fractionated SRT in combination with temozolomide [58]. Cuneo et al. treated 63 patients with recurrent HGG (49/63 GBM) with stereotactic radiosurgery and adjuvant bevacizumab, and median PFS and OS from SRS were 6 and 10 months, respectively [59]. The 1 year OS from SRS for patients with GBM who received bevacizumab was 50 versus $22 \%$ for patients not receiving adjuvant bevacizumab.

Given the increasing number of institutional series examining the safety and efficacy of reirradiation of patients with recurrent $\mathrm{HGG}$, a prospective study corroborating the aforementioned results would likely effect a paradigm shift in how patients with recurrent disease are treated.

\section{Particle therapy}

Particle therapy, such as proton and carbon ion RT, has an inherent physical advantage, the so-called Bragg peak, which allows for increase in energy deposition at the end of beam's 
path [60]. Favorable dose distribution with these modalities is achieved by 'spreading' the Bragg peak to ensure tumor volume coverage, but allowing for a steep dose fall-off at the field borders, which implies more sparing of organs at risks compared with photon therapy. Therefore, particle therapy is being considered as an attractive modality for glioma patients, because it may allow for delivery of higher dose of radiation to the tumor, but with reduced toxicity to surrounding normal tissues. Protons and carbon ions have a higher linear energy transfer than photons, a measure of particle's ability to induce DNA damage per unit length, although relative biologic effectiveness of protons is similar to that of photons [61]. By contrast, carbon ions have a higher relative biologic effectiveness compared with protons. This biological advantage leads to greater degree of irreparable DNA damage. In addition, the radiation effects or these modalities are less dependent on oxygen concentration in tumor, and thereby more effective against the hypoxic tumor cells $[62,63]$.

Clinical studies of proton therapy have been performed for several types of tumors, including gliomas [64]. Fitzek et al. conducted a Phase II study of 23 GBM patients treated with radiation dose-equivalent of 90 Gy equivalent $(\mathrm{GyE})$ utilizing protons and photons [65]. The median survival was 20 months, although most patients experienced radiation necrosis within high radiation dose area. Recently Mizumoto et al. conducted a Phase I/II study of 20 GBM patients treated with hyperfractionated concomitant boost proton therapy (96.6 GyE in 56 fractions) [66]. The 2 year OS was $45.3 \%$ and median survival time was 21.6 months. They concluded that this treatment was tolerable and beneficial. Fitzek et al. used a similar approach on patients with grade 2 and 3 gliomas treated by dose-escalation with proton and photon therapy (68.2-79.7 GyE) [67]. However, this study failed to improve outcome compared with historical studies. Hug et al. reported on 27 pediatric LGGs treated with proton therapy (50.4-63.0 GyE) [68]. The authors suggested that proton therapy was effective and safe for these patients. Given these findings in relatively small cohorts, proton therapy for glioma patients appears to have at least as favorable an outcome as photons and is well tolerated, but the rates of radiation necrosis are higher. In order to discern whether a meaningful difference in patient outcomes exists, a direct comparison between proton and photon therapies for glioma patients needs to be explored. Further studies are warranted to establish the efficacy and safety of proton therapy for glioma patients.

Theoretically, carbon ion therapy is also expected to improve the prognosis in glioma patients, owing to its physiological and biological advantages. Preclinical study demonstrated that carbon ion is more effective in killing GBM cells compared with photons [69]. Mizoe et al. conducted a Phase I/II studies of carbon ion therapy for 48 patients with malignant gliomas [70]. This study applied carbon ions as a boost therapy (16.8-24.8 GyE) following $50 \mathrm{~Gy}$ of photon therapy with nimustine hydrochloride. Median survival times of anaplastic glioma and GBM were 35 and 17 months, respectively. High carbon dose group (24.8 GyE) had better OS, and toxicity was generally low. Concurrent and adjuvant TMZ plus photon therapy is the standard treatment for GBM, but the efficacy of adding TMZ to carbon ion therapy has not yet been demonstrated in clinical study. In vitro studies suggest that carbon ion and TMZ synergistically decrease survival in GBM cells [71]. Combs et al. are conducting a randomized Phase II study in patients with GBM, comparing carbon ion therapy (18 GyE in 6 fractions) with proton therapy (10 GyE in 5 fractions) as a boost 
following 50 Gy of photon therapy with concurrent TMZ [72]. In the near future, this study will show the efficacy of particle therapies with TMZ for GBM patients.

Although particle therapies were previously available in only a handful institutions, proton therapy is currently offered in tens of centers worldwide, including nine in the USA, while the carbon ion therapy is currently available in Japan and Germany [73]. Having increased access to particle therapy will enable investigators to perform more clinical studies in the future, and help answer the question of their relative efficacy against glial and other tumors.

\section{Future perspective}

As we learn more about cellular pathways and effectors involved in gliomagenesis, there will likely be a paradigm shift from the uniform standard-of-care treatment for all patients to a more individualized treatment based on molecular biomarkers. The aforementioned targeted therapies will help us devise a more effective treatment strategy by tackling the underpinnings of resistance of malignant gliomas. The challenge before the scientific and clinical community will be to identify the key targets and formulate therapy accordingly. Foregoing the 'one-size-fits-all' approach will lessen the harm done to the patients, as we know from the clinical trials that both standard and novel therapies may cause serious toxicities. Several of the newer agents warrant testing in a larger and randomized setting to truly discern their efficacy and safety, with the overarching hope of improving our patients' prognosis. The most recent update from Stupp and colleagues regarding integrin inhibition with addition of cilengitide to standard chemoradiotherapy shows promise to potentially become the new standard-of-care for patients with GBM, suggesting that the most effective strategy is to target both the extracellular (e.g., integrin) and intracellular effectors.

Moreover, just as the methylation status of the $M G M T$ promoter did, greater characterization of gene expression by epigenetic regulation may help us elucidate additional mechanisms of resistance or sensitivity to therapy.

In summary, gaining a better understanding of the molecular brain tumor population(s) that benefit from each targeted therapy will lead to more effective personalized therapy. It is hoped that a more targeted therapeutic approach will overcome the current limitations in the treatment of patients with malignant gliomas and result in a better prognosis for patients with brain tumors.

\section{Bibliography}

Papers of special note have been highlighted as:

of interest

घ of considerable interest

1. Louis DN, Ohgaki H, Wiestler OD, et al. The 2007 WHO classification of tumours of the central nervous system. Acta Neuropathol. 2007; 114(2):97-109. [PubMed: 17618441]

2. Claus EB, Black PM. Survival rates and patterns of care for patients diagnosed with supratentorial low-grade gliomas: Data from the SEER program, 1973-2001. Cancer. 2006; 106(6):1358-1363. [PubMed: 16470608] 
3. Berger MS, Deliganis AV, Dobbins J, Keles GE. The effect of extent of resection on recurrence in patients with low grade cerebral hemisphere gliomas. Cancer. 1994; 74(6):1784-1791. [PubMed: 8082081]

4. Karim AB, Afra D, Cornu P, et al. Randomized trial on the efficacy of radiotherapy for cerebral low-grade glioma in the adult: European Organization for Research And Treatment of Cancer Study 22845 with the Medical Research Council Study BRO4: an interim analysis. Int. J. Radiat. Oncol. Biol. Phys. 2002; 52(2):316-324. [PubMed: 11872276] ש Key paper on treatment of low grade gliomas.

5. van den Bent MJ, Afra D, de Witte O, et al. Long-term efficacy of early versus delayed radiotherapy for low-grade astrocytoma and oligodendroglioma in adults: the EORTC 22845 randomised trial. Lancet. 2005; 366(9490):985-990. [PubMed: 16168780] $\square$ Key paper on immediate versus deferred radiotherapy in patients with low grade glioma.

6. Pignatti F, van den Bent M, Curran D, et al. Prognostic factors for survival in adult patients with cerebral low-grade glioma. J. Clin. Oncol. 2002; 20(8):2076-2084. [PubMed: 11956268] — Metaanalysis outlining clinical factors to help decide whether to recommend immediate versus deferred radiotherapy in patients with low grade gliomas.

7. Shaw E, Arusell R, Scheithauer B, et al. Prospective randomized trial of low- versus high-dose radiation therapy in adults with supratentorial low-grade glioma: initial report of a North Central Cancer Treatment Group/Radiation Therapy Oncology Group/Eastern Cooperative Oncology Group study. J. Clin. Oncol. 2002; 20(9):2267-2276. [PubMed: 11980997] $\mathbf{0}$ Key paper assessing doseresponse relationships in low grade gliomas.

8. Karim AB, Maat B, Hatlevoll R, et al. A randomized trial on doseu-response in radiation therapy of low-grade cerebral glioma: European Organization for Research and Treatment of Cancer (EORTC) study 22844. Int. J. Radiat. Oncol. Biol. Phys. 1996; 36(3):549-556. [PubMed: 8948338] ם Key paper assessing dose-response relationships in low grade gliomas.

9. Kesari S, Schiff D, Drappatz J, et al. Phase II study of protracted daily temozolomide for low-grade gliomas in adults. Clin. Cancer Res. 2009; 15(1):330-337. [PubMed: 19118062]

10. Pouratian N, Gasco J, Sherman JH, Shaffrey ME, Schiff D. Toxicity and efficacy of protracted low dose temozolomide for the treatment of low grade gliomas. J. Neurooncol. 2007; 82(3):281-288. [PubMed: 17082887]

11. Shaw, EG.; Wang, M.; Coons, S., et al. Final report of radiation therapy oncology group protocol 9802: radiation therapy (RT) versus RT + procarbazine, CCNU and vincristine (PCV) chemotherapy for adult low-grade glioma (LGG). Presented at: 2008 ASCO National Meeting; Chicago, IL, USA. 30 May-3 June 2008;

12. Scanlon PW, Taylor WF. Radiotherapy of intracranial astrocytomas: analysis of 417 cases treated from 1960 through 1969. Neurosurgery. 1979; 5(3):301-308. [PubMed: 228216]

13. Fine HA, Dear KB, Loeffler JS, Black PM, Canellos GP. Meta-analysis of radiation therapy with and without adjuvant chemotherapy for malignant gliomas in adults. Cancer. 1993; 71(8):25852597. [PubMed: 8453582]

14. Stupp R, Mason WP, van den Bent MJ, et al. Radiotherapy plus concomitant and adjuvant temozolomide for glioblastoma. N. Engl. J. Med. 2005; 352(10):987-996. [PubMed: 15758009] - Key trial that effected a paradigm shift in the treatment of grade IV glioma.

15. Hegi ME, Diserens AC, Gorlia T, et al. MGMT gene silencing and benefit from temozolomide in glioblastoma. N. Engl. J. Med. 2005; 352(10):997-1003. [PubMed: 15758010] 口 Molecular prognostic factors in patients with grade IV glioma.

16. Stupp R, Hegi ME, Mason WP, et al. Effects of radiotherapy with concomitant and adjuvant temozolomide versus radiotherapy alone on survival in glioblastoma in a randomised Phase III study: 5-year analysis of the EORTC-NCtrial IC. Lancet Oncol. 2009; 10(5):459-466. [PubMed: 19269895]

17. Clarke JL, Iwamoto FM, Sul J, et al. Randomized Phase II trial of chemoradiotherapy followed by either dose-dense or metronomic temozolomide for newly diagnosed glioblastoma. J. Clin. Oncol. 2009; 27(23):3861-3867. [PubMed: 19506159]

18. van den Bent MJ, Carpentier AF, Brandes AA, et al. Adjuvant procarbazine, lomustine, and vincristine improves progression-free survival but not overall survival in newly diagnosed anaplastic oligodendrogliomas and oligoastrocytomas: a randomized european organisation for 
research and treatment of cancer Phase I trial II. J. Clin. Oncol. 2006; 24(18):2715-2722. [PubMed: 16782911]

19. Cairncross JG, Ueki K, Zlatescu MC, et al. Specific genetic predictors of chemotherapeutic response and survival in patients with anaplastic oligodendrogliomas. J. Natl Cancer Inst. 1998; 90(19):1473-1479. [PubMed: 9776413]

20. Cairncross G, Berkey B, Shaw E, et al. Phase III trial of chemotherapy plus radiotherapy compared with radiotherapy alone for pure and mixed anaplastic oligodendroglioma: Intergroup Radiation Therapy Oncology Group Trial 9402. J. Clin. Oncol. 2006; 24(18):2707-2714. [PubMed: 16782910]

21. Smith JS, Perry A, Borell TJ, et al. Alterations of chromosome arms $1 \mathrm{p}$ and $19 \mathrm{q}$ as predictors of survival in oligodendrogliomas, astrocytomas, and mixed oligoastrocytomas. J. Clin. Oncol. 2000; 18(3):636-645. [PubMed: 10653879]

22. Ino Y, Betensky RA, Zlatescu MC, et al. Molecular subtypes of anaplastic oligodendroglioma: implications for patient management at diagnosis. Clin. Cancer Res. 2001; 7(4):839-845. [PubMed: 11309331]

23. Snuderl M, Eichler AF, Ligon KL, et al. Polysomy for chromosomes 1 and 19 predicts earlier recurrence in anaplastic oligodendrogliomas with concurrent 1p/19q loss. Clin. Cancer Res. 2009; 15(20):6430-6437. [PubMed: 19808867]

24. Vogelbaum MA, Berkey B, Peereboom D, et al. Phase II trial of preirradiation and concurrent temozolomide in patients with newly diagnosed anaplastic oligodendrogliomas and mixed anaplastic oligoastrocytomas: RTOG BR0131. Neuro. Oncol. 2009; 11(2):167-175. [PubMed: 18779504]

25. Perez-Soler R. HER1/EGFR targeting: refining the strategy. Oncologist. 2004; 9(1):58-67. [PubMed: 14755015]

26. Rich JN, Reardon DA, Peery T, et al. Phase II trial of gefitinib in recurrent glioblastoma. J. Clin. Oncol. 2004; 22(1):133-142. [PubMed: 14638850]

27. van den Bent MJ, Brandes AA, Rampling R, et al. Randomized Phase II trial of erlotinib versus temozolomide or carmustine in recurrent glioblastoma: EORTC Brain Tumor Group Study 26034. J. Clin. Oncol. 2009; 27(8):1268-1274. [PubMed: 19204207]

28. Bianco C, Tortora G, Bianco R, et al. Enhancement of antitumor activity of ionizing radiation by combined treatment with the selective epidermal growth factor receptor-tyrosine kinase inhibitor ZD1839 (IRESSA). Clin. Cancer Res. 2002; 8(10):3250-3258. [PubMed: 12374696]

29. Chakravarti, A. An update of Phase II results from RTOG 0211: a Phase I/II study of gefitinib with radiotherapy in newly diagnosed glioblastoma. Presented at: 2006 ASCO Annual Meeting; Atlanta, GA, USA. 2-6 June 2006;

30. Prados MD, Chang SM, Butowski N, et al. Phase II study of erlotinib plus temozolomide during and after radiation therapy in patients with newly diagnosed glioblastoma multiforme or gliosarcoma. J. Clin. Oncol. 2009; 27(4):579-584. [PubMed: 19075262]

31. Peereboom DM, Shepard DR, Ahluwalia MS, et al. Phase II trial of erlotinib with temozolomide and radiation in patients with newly diagnosed glioblastoma multiforme. J. Neurooncol. 2010; 98(1):93-99. [PubMed: 19960228]

32. Brown PD, Krishnan S, Sarkaria JN, et al. Phase I/II trial of erlotinib and temozolomide with radiation therapy in the treatment of newly diagnosed glioblastoma multiforme: North Central Cancer Treatment Group Study N0177. J. Clin. Oncol. 2008; 26(34):5603-5609. [PubMed: 18955445]

33. Mellinghoff IK, Wang MY, Vivanco I, et al. Molecular determinants of the response of glioblastomas to EGFR kinase inhibitors. N. Engl. J. Med. 2005; 353(19):2012-2024. [PubMed: 16282176]

34. Weller M, Felsberg J, Hartmann C, et al. Molecular predictors of progression-free and overall survival in patients with newly diagnosed glioblastoma: a prospective translational study of the German Glioma Network. J. Clin. Oncol. 2009; 27(34):5743-5750. [PubMed: 19805672]

35. Tabatabai G, Stupp R, van den Bent MJ, et al. Molecular diagnostics of gliomas: the clinical perspective. Acta Neuropathol. 2010; 120(5):585-592. [PubMed: 20862485] 
36. Sampson JH, Heimberger AB, Archer GE, et al. Immunologic escape after prolonged progressionfree survival with epidermal growth factor receptor variant III peptide vaccination in patients with newly diagnosed glioblastoma. J. Clin. Oncol. 2010; 28(31):4722-4729. [PubMed: 20921459]

37. Ahluwalia MS, Gladson CL. Progress on antiangiogenic therapy for patients with malignant glioma. J. Oncol. 2010; 2010:689018. [PubMed: 20379377]

38. Vredenburgh JJ, Desjardins A, Herndon JE 2nd, et al. Bevacizumab plus irinotecan in recurrent glioblastoma multiforme. J. Clin. Oncol. 2007; 25(30):4722-4729. [PubMed: 17947719]

39. Friedman HS, Prados MD, Wen PY, et al. Bevacizumab alone and in combination with irinotecan in recurrent glioblastoma. J. Clin. Oncol. 2009; 27(28):4733-4740. [PubMed: 19720927]

40. Lai A, Tran A, Nghiemphu PL, et al. Phase II study of bevacizumab plus temozolomide during and after radiation therapy for patients with newly diagnosed glioblastoma multiforme. J. Clin. Oncol. 2011; 29(2):142-148. [PubMed: 21135282]

41. Taga T, Suzuki A, Gonzalez-Gomez I, et al. a v-integrin antagonist EMD 121974 induces apoptosis in brain tumor cells growing on vitronectin and tenascin. Int. J. Cancer. 2002; 98(5): 690-697. [PubMed: 11920637]

42. Reardon DA, Fink KL, Mikkelsen T, et al. Randomized Phase II study of cilengitide, an integrintargeting arginine-glycine-aspartic acid peptide, in recurrent glioblastoma multiforme. J. Clin. Oncol. 2008; 26(34):5610-5617. [PubMed: 18981465]

43. Stupp R, Hegi ME, Neyns B, et al. Phase I/IIa study of cilengitide and temozolomide with concomitant radiotherapy followed by cilengitide and temozolomide maintenance therapy in patients with newly diagnosed glioblastoma. J. Clin. Oncol. 2010; 28(16):2712-2718. [PubMed: 20439646]

44. Ishiuchi S, Tsuzuki K, Yoshida Y, et al. Blockage of $\left.\mathrm{ca}^{2+}\right)$-permeable AMPA receptors suppresses migration and induces apoptosis in human glioblastoma cells. Nat. Med. 2002; 8(9): 971-978. [PubMed: 12172541]

45. Grossman SA, Ye X, Chamberlain M, et al. Talampanel with standard radiation and temozolomide in patients with newly diagnosed glioblastoma: a multicenter Phase II trial. J. Clin. Oncol. 2009; 27(25):4155-4161. [PubMed: 19636006]

46. Yin D, Zhou H, Kumagai T, et al. Proteasome inhibitor PS-341 causes cell growth arrest and apoptosis in human glioblastoma multiforme (GBM). Oncogene. 2005; 24(3):344-354. [PubMed: 15531918]

47. Kubicek GJ, Werner-Wasik M, Machtay M, et al. Phase I trial using proteasome inhibitor bortezomib and concurrent temozolomide and radiotherapy for central nervous system malignancies. Int. J. Radiat. Oncol. Biol. Phys. 2009; 74(2):433-439. [PubMed: 19084346]

48. Nuutinen J, Sonninen P, Lehikoinen $P$, et al. Radiotherapy treatment planning and long-term follow-up with [(11)c]methionine pet in patients with low-grade astrocytoma. Int. J. Radiat. Oncol. Biol. Phys. 2000; 48(1):43-52. [PubMed: 10924970]

49. Grosu AL, Weber WA. PET for radiation treatment planning of brain tumours. Radiother. Oncol. 2010; 96(3):325-327. [PubMed: 20728952]

50. Grosu AL, Weber WA, Riedel E, et al. L-(methyl-11c) methionine positron emission tomography for target delineation in resected high-grade gliomas before radiotherapy. Int. J. Radiat. Oncol. Biol. Phys. 2005; 63(1):64-74. [PubMed: 16111573]

51. Astner ST, Shi K, Vaupel P, Molls M. Imaging of tumor physiology: impacts on clinical radiation oncology. Exp. Oncol. 2010; 32(3):149-152. [PubMed: 21403609]

52. Bloom HJ. Combined modality therapy for intracranial tumors. Cancer. 1975; 35(1):111-120. [PubMed: 162849]

53. Hermanto U, Frija EK, Lii MJ, Chang EL, Mahajan A, Woo SY. Intensity-modulated radiotherapy (IMRT) and conventional three-dimensional conformal radiotherapy for high-grade gliomas: does IMRT increase the integral dose to normal brain? Int. J. Radiat. Oncol. Biol. Phys. 2007; 67(4): 1135-1144. [PubMed: 17208388]

54. Hall EJ, Wuu CS. Radiation-induced second cancers: the impact of 3D-CRT and IMRT. Int. J. Radiat. Oncol. Biol. Phys. 2003; 56(1):83-88. [PubMed: 12694826]

55. D'Souza WD, Rosen II. Nontumor integral dose variation in conventional radiotherapy treatment planning. Med. Phys. 2003; 30(8):2065-2071. [PubMed: 12945972] 
56. Fogh SE, Andrews DW, Glass J, et al. Hypofractionated stereotactic radiation therapy: an effective therapy for recurrent high-grade gliomas. J. Clin. Oncol. 2010; 28(18):3048-3053. [PubMed: 20479391]

57. Combs SE, Gutwein S, Thilmann C, Debus J, Schulz-Ertner D. Reirradiation of recurrent who grade III astrocytomas using fractionated stereotactic radiotherapy (FSRT). Strahlenther. Onkol. 2005; 181(12):768-773. [PubMed: 16362786]

58. Combs SE, Bischof M, Welzel T, et al. Radiochemotherapy with temozolomide as reirradiation using high precision fractionated stereotactic radiotherapy (FSRT) in patients with recurrent gliomas. J. Neurooncol. 2008; 89(2):205-210. [PubMed: 18461281]

59. Cuneo KC, Vredenburgh JJ, Sampson JH, et al. Safety and efficacy of stereotactic radiosurgery and adjuvant bevacizumab in patients with recurrent malignant gliomas. Int. J. Radiat. Oncol. Biol. Phys. 2011 doi:10.1016/j. ijrobp.2010.12.074. Epub ahead of print.

60. Schulz-Ertner D, Tsujii H. Particle radiation therapy using proton and heavier ion beams. J. Clin. Oncol. 2007; 25(8):953-964. [PubMed: 17350944]

61. Paganetti H, Niemierko A, Ancukiewicz M, et al. Relative biological effectiveness (RBE) values for proton beam therapy. Int. J. Radiat. Oncol. Biol. Phys. 2002; 53(2):407-421. [PubMed: 12023146]

62. Ando K, Koike S, Ohira C, et al. Accelerated reoxygenation of a murine fibrosarcoma after carbon-ion radiation. Int. J. Radiat. Biol. 1999; 75(4):505-512. [PubMed: 10331856]

63. Nakano T, Suzuki Y, Ohno T, et al. Carbon beam therapy overcomes the radiation resistance of uterine cervical cancer originating from hypoxia. Clin. Cancer Res. 2006; 12(7 Pt 1):2185-2190. [PubMed: 16609033]

64. Brada M, Pijls-Johannesma M, De Ruysscher D. Current clinical evidence for proton therapy. Cancer J. 2009; 15(4):319-324. [PubMed: 19672149]

65. Fitzek MM, hornton AF, Rabinov JD, et al. Accelerated fractionated proton/photon irradiation to 90 cobalt gray equivalent for glioblastoma multiforme: results of a Phase II prospective trial. J. Neurosurg. 1999; 91(2):251-260. [PubMed: 10433313]

66. Mizumoto M, Tsuboi K, Igaki H, et al. Phase I/II trial of hyperfractionated concomitant boost proton radiotherapy for supratentorial glioblastoma multiforme. Int. J. Radiat. Oncol. Biol. Phys. 2010; 77(1):98-105. [PubMed: 19695794]

67. Fitzek MM, Thornton AF, Harsh GT, et al. Dose-escalation with proton/photon irradiation for daumas-duport lower-grade glioma: Results of an institutional Phase I/II trial. Int. J. Radiat. Oncol. Biol. Phys. 2001; 51(1):131-137. [PubMed: 11516862]

68. Hug EB, Muenter MW, Archambeau JO, et al. Conformal proton radiation therapy for pediatric low-grade astrocytomas. Strahlenther. Onkol. 2002; 178(1):10-17. [PubMed: 11977386]

69. Iwadate Y, Mizoe J, Osaka Y, Yamaura A, Tsujii H. High linear energy transfer carbon radiation effectively kills cultured glioma cells with either mutant or wild-type p53. Int. J. Radiat. Oncol. Biol. Phys. 2001; 50(3):803-808. [PubMed: 11395250]

70. Mizoe JE, Tsujii H, Hasegawa A, et al. Phase I/II clinical trial of carbon ion radiotherapy for malignant gliomas: combined x-ray radiotherapy, chemotherapy, and carbon ion radiotherapy. Int. J. Radiat. Oncol. Biol. Phys. 2007; 69(2):390-396. [PubMed: 17459607]

71. Combs SE, Bohl J, Elsasser T, et al. Radiobiological evaluation and correlation with the local effect model (LEM) of carbon ion radiation therapy and temozolomide in glioblastoma cell lines. Int. J. Radiat. Biol. 2009; 85(2):126-137. [PubMed: 19280465]

72. Combs SE, Kieser M, Rieken S, et al. Randomized Phase II study evaluating a carbon ion boost applied after combined radiochemotherapy with temozolomide versus a proton boost after radiochemotherapy with temozolomide in patients with primary glioblastoma: the cleopatra trial. BMC Cancer. 2010; 10:478. [PubMed: 20819220]

73. Okada T, Kamada T, Tsuji H, et al. Carbon ion radiotherapy: clinical experiences at national institute of radiological science (NIRS). J. Radiat. Res. (Tokyo). 2010; 51(4):355-364. [PubMed: 20508375]

74. Gruber ML, Raza S, Gruber D, et al. Bevacizumab in combination with radiotherapy plus concomitant and adjuvant temozolomide for newly diagnosed glioblastoma: update progressionfree survival, overall survival, and toxicity. J. Clin. Oncol. 2009; 27:15. Abstract 2017. 
75. Gilbert MR, Wang M, Aldape K, et al. RTOG 0625: a phase II study of bevacizumab with irinotecan in recurrent glioblastoma (GBM). J. Clin. Oncol. 2009; 27:15. Abstract 2011.

76. Soffietti R, Rudà R, Trevisan E, et al. Phase II study of bevacizumab and nitrosourea in patients with recurrent malignant glioma: a multicenter Italian study. J. Clin. Oncol. 2009; 27:15. Abstract 2012.

77. Raizer JJ, Grimm S, Rice L, et al. A phase II trial of single-agent bevacizumab given every 3 weeks for recurrent malignant gliomas. J. Clin. Oncol. 2009; 27:15. Abstract 2044.

78. Altaha R, Almubarak M, Newton MD, et al. A pilot study of fosbretabulin with bevacizumab in recurrent high-grade gliomas. J. Clin. Oncol. 2010; 28:15. Abstract TPS147. [PubMed: 19933920]

79. Bogdahn U, Schneider T, Oliushine V, et al. Randomized, active-controlled phase IIb study with trabedersen (AP 12009) in recurrent or refractory high-grade glioma patients: Basis for phase III endpoints. J. Clin. Oncol. 2009; 27:15. Abstract 2037.

80. Chi AS, Gerstner ER, Eichler AF, et al. Phase Ib study of cediranib in combination with daily temozolomide and radiation in patients with newly diagnosed glioblastoma. J. Clin. Oncol. 2009; 27 Abstract e13010.

81. Brandes AA, Stupp R, Hau P, et al. EORTC study 26041-22041: phase I/II study on concomitant and adjuvant temozolomide (TMZ) and radiotherapy (RT) with PTK787/ZK222584 (PTK/ZK) in newly diagnosed glioblastoma. Eur. J. Cancer. 2010; 46(2):348-354. [PubMed: 19945857]

82. Batchelor T, Eichler AF, Plotkin SR, et al. Phase I trial of vatalanib (PTK787) in combination with standard radiation and temozolomide in patients with newly diagnosed glioblastoma. J. Clin. Oncol. 2009; 27 Abstract 2035.

83. Schiff D, Reardon DA, Kesari S, et al. Phase II study of CT-322, a targeted biologic inhibitor of VEGFR-2 based on a domain of human fibronectin, in recurrent glioblastoma (rGBM). J. Clin. Oncol. 2010; 28:15. Abstract 2011. [PubMed: 19933920]

84. Hainsworth JD, Ervin T, Friedman E, et al. Concurrent radiotherapy and temozolomide followed by temozolomide and sorafenib in the first-line treatment of patients with glioblastoma multiforme. Cancer. 2010; 116(15):3663-3669. [PubMed: 20564147]

85. Friedman HS, Vredenburgh JJ, Desjardins A, et al. A phase I study of sunitinib plus irinotecan in the treatment of patients with recurrent malignant glioma. J. Clin. Oncol. 2009; 27:15. Abstract e13024.

86. Neyns B, Chaskis C, Dujardin M, et al. Phase II trial of sunitinib malate in patients with temozolomide refractory recurrent high-grade glioma. J. Clin. Oncol. 2009; 27:15. Abstract 2038.

87. Supko JG, Grossman SA, Peereboom DM, et al. Feasibility and phase I trial of tandutinib in patients with recurrent glioblastoma. J. Clin. Oncol. 2009; 27:15. Abstract 2039.

88. Wick W, Puduvalli VK, Chamberlain MC, et al. Phase III study of enzastaurin compared with lomustine in the treatment of recurrent intracranial glioblastoma. J. Clin. Oncol. 2010; 28(7):11681174. [PubMed: 20124186]

89. Butowski NA, Lamborn K, Chang S, et al. Phase II and pharmacogenomics study of enzastaurin plus temozolomide and radiation therapy in patients with glioblastoma multiforme or gliosarcoma. J. Clin. Oncol. 2009; 27:15. Abstract 2020.

90. Sarkaria JN, Galanis E, Wu W, et al. NCCTG phase I trial of temsirolimus (CCI-779) and temozolomide (TMZ) in combination with radiation therapy (RT) in newly diagnosed glioblastoma multiforme (GBM) patients. J. Clin. Oncol. 2009; 27:15. Abstract 2019.

91. Mason WP, MacNeil M, Easaw J, et al. A phase I study of temozolomide (TMZ) and RAD001 in patients (pts) with glioblastoma multiforme (GBM). J. Clin. Oncol. 2009; 27:15. Abstract 2036.

92. Fiveash JB, Chowdhary SA, Peereboom D. NABTT-0702: A phase II study of R-(-)-gossypol (AT-101) in recurrent glioblastoma multiforme (GBM). J. Clin. Oncol. 2009; 27:15. Abstract 2010.

93. Lamar RE, Spigel DR, Burris HA, et al. Phase II trial of radiation therapy/temozolomide followed by temozolomide/sorafenib in the first-line treatment of glioblastoma multiforme (GBM). J. Clin. Oncol. 2010; 27:15. Abstract 2018.

94. Desjardins A, Reardon DA, Gururangan S, et al. Phase I trial combining SCH 66336 to temozolomide (TMZ) for patients with grade 3 or 4 malignant gliomas (MG). J. Clin. Oncol. 2009; 27 Abstract e13004. 
95. Chinnaiyan P, Chowdhary S, Brem S, et al. A phase I trial of vorinostat in combination with bevacizumab and irinotecan in recurrent glioblastoma. J. Clin. Oncol. 2010; 28:15. Abstract TPS150. [PubMed: 19933920]

96. Blakeley JO, Ye X, Grossman SA, et al. Poly (ADP-ribose) polymerase-1 (PARP1) inhibitor BSI-201 in combination with temozolomide (TMZ) in malignant glioma. J. Clin. Oncol. 2010; 28:15. Abstract 2012. [PubMed: 19933920]

97. Sathornsumetee S, Desjardins A, Vredenburgh JJ, et al. Phase II study of bevacizumab plus erlotinib for recurrent malignant gliomas. J. Clin. Oncol. 2009; 27:15. Abstract 2045.

98. Drappatz J, Norden AD, Wong ET. Phase I study of vandetanib with radiation therapy and temozolomide for newly diagnosed glioblastoma. J. Clin. Oncol. 2009; 27:15. Abstract 2031.

99. Herndon J, Vredenburgh J, Reardon D, et al. Phase I trial of vendetanib and oral etoposide for recurrent malignant gliomas. J. Clin. Oncol. 2009; 27 Abstract e13016.

100. Kirkpatrick JP, Vredenburgh JJ, Desjardins A, et al. Phase I study of vandetanib, imatinib mesylate, and hydroxyurea for recurrent malignant glioma. J. Clin. Oncol. 2009; 27 Abstract e13007.

101. Mcnicol KA, Kreisl TN, Iwamoto FM, et al. Phase I/II study of vandetanib for patients with recurrent malignant gliomas. J. Clin. Oncol. 2010; 28:15. Abstract 2083. [PubMed: 19933920]

102. Hasselbalch B, Lassen U, Hansen S, et al. Cetuximab, bevacizumab, and irinotecan for patients with primary glioblastoma and progression after radiation therapy and temozolomide: a phase II trial. Neuro. Oncol. 2010; 12(5):508-516. [PubMed: 20406901]

103. Chang SM, Kuhn J, Lamborn K, et al. Phase I/II study of erlotinib and temsirolimus for patients with recurrent malignant gliomas (MG) (NABTC 04-02). J. Clin. Oncol. 2009; 27:15. Abstract 2004.

104. Reardon D, Desjardins A, Vredenburgh JJ, et al. Bevacizumab plus etoposide among recurrent malignant glioma patients: Phase II study final results. J. Clin. Oncol. 2009; 27:15. Abstract 2046.

105. Prados M, Gilbert M, Kuhn J, et al. Phase I/II study of sorefenib and erlotinib for patients with recurrent glioblastoma (GBM) (NABTC 05-02). J. Clin. Oncol. 2009; 27:15. Abstract 2005.

106. Wen PY, Cloughesy T, Kuhn J, et al. Phase I/ II study of sorafenib and temsirolimus for patients with recurrent glioblastoma (GBM) (NABTC 05-02). J. Clin. Oncol. 2009; 27:15. Abstract 2006.

107. De Groot JF, Prados M, Urquhart T, et al. A Phase II study of XL184 in patients (pts) with progressive glioblastoma multiforme (GBM) in first or second relapse. J. Clin. Oncol. 2009; 27:15. Abstract 2047.

108. Wen PY, Prados M, Schiff D, et al. Phase II study of XL184 (BMS 907351), an inhibitor of MET, VEGFR2, and RET, in patients (pts) with progressive glioblastoma (GB). J. Clin. Oncol. 2010; 28:15. Abstract 2006. [PubMed: 19933920]

109. Frentzas SN, Groves MD, Barriuso J, et al. Pazopanib and lapatinib in patients with relapsed malignant glioma: Results of a phase I/II study. J. Clin. Oncol. 2009; 27:15. Abstract 2040.

110. Fink K, Mikkelsen T, Nabors LB, et al. Long-term effects of cilengitide, a novel integrin inhibitor, in recurrent glioblastoma: A randomized phase IIa study. J. Clin. Oncol. 2009; 28:15. Abstract 2010. [PubMed: 19933920]

111. Drappatz J, Brenner AJ, Rosenfeld S, et al. ANG1005: Results of a phase I study in patients with recurrent malignant glioma. J. Clin. Oncol. 2010; 28:15. Abstract 2009. [PubMed: 19933920]

112. Benouaich-Amiel A, Mazza E, Massard C, et al. Phase I study of the oral CDK-TRKA inhibitor PHA-848125 in recurrent malignant glioma (MG). J. Clin. Oncol. 2010; 28:15. Abstract 2087. [PubMed: 19933920]

\section{Websites}

201. CFaF American Cancer Society.www.cancer.org/acs/groups/content/@nho/documents/ document/acspc-024113.pdf

202. ASCO Annual Meeting 2009 and 2010, CNS Tumors Abstracts Section. www.asco.org 


\section{Executive summary}

\section{Incidence of brain gliomas is increasing}

- Oligodendrocytic histology portends better survival compared with astrocytic histology, especially if $1 \mathrm{p} 19 \mathrm{q}$ deleted.

- Marginal improvement in survival of patients with high grade gliocytoma owing to complex mechanisms of tumor resistance and migration.

- Standard of care treatment for high-grade gliocytoma is maximum safe resection, followed by chemoradiotherapy and maintenance temozolomide.

- Patients with methylated $M G M T$ promoter have a better prognosis.

- Optimizing adjuvant systemic therapy regimen is a potential strategy to improve outcomes in patients with unmethylated $M G M T$ promoter.

Targeted therapy against several glioma signaling pathways may improve survival

Addition of anti-VEGF and anti-integrin therapy to standard of care treatment currently tested in Phase III trial.

- Targeted therapy currently explored in clinical trials aims at both intra- and extra-cellular targets.

Imaging of gliomas cannot always discern radiation-induced tumor necrosis from tumor progression

- Radiolabeled amino acid tracers have increased sensitivity and specificity in diagnosing gliomas, as well as progression versus treatment-related effect.

- Methionine tracer has high uptake by tumor cells, as does O-(2[18F]fluoroethyl)---tyrosine tracer (18F-FET).

- MET- and 18F-FET PET are increasingly used in a diagnostic and treatment planning capacity.

Intensity modulated radiotherapy is the most sophisticated way of delivering radiotherapy to gliomas

- Intensity modulated radiotherapy is optimized to protect adjacent brain parenchyma from high doses of radiotherapy while delivering adequate doses to the target area.

- The dose fall-off at the edge of treatment volume is more pronounced than with conventional three-dimensional conformal RT.

\section{Particle therapy currently tested in a limited number of centers}

- Particle therapy has higher relative biological effectiveness, imparting a greater degree of irreparable DNA damage.

Proton and carbon ion radiotherapy has the so-called Bragg peak, allowing for increase in energy deposition at the end of the beam's path. 


More sparing of unaffected organs/tissue at risk compared with photon
therapy.
May allow for for delivery of higher dose of radiation to the tumor, with
reduced toxicity to surrounding tissue.
Better understanding of pathways involved in gliomagenesis, invasion and
treatment resistance will allow for better targeting.
Greater characterization of epigenetic regulation may help elucidate
additional mechanisms of resistance or sensitivity to therapy.
The challenge before the scientific and clinical community will be to identify
the key targets and formulate therapy accordingly, thereby foregoing the
'one-size-fits-all' approach.
Identifying the patient subsets that benefit from different targeted therapy
will lead to more effective personalized therapy.




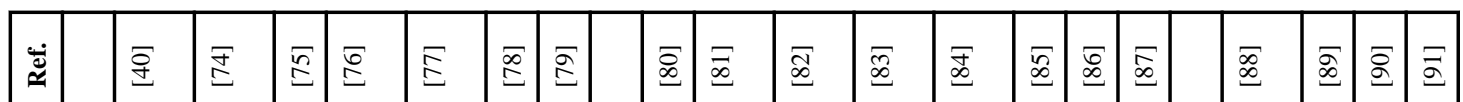
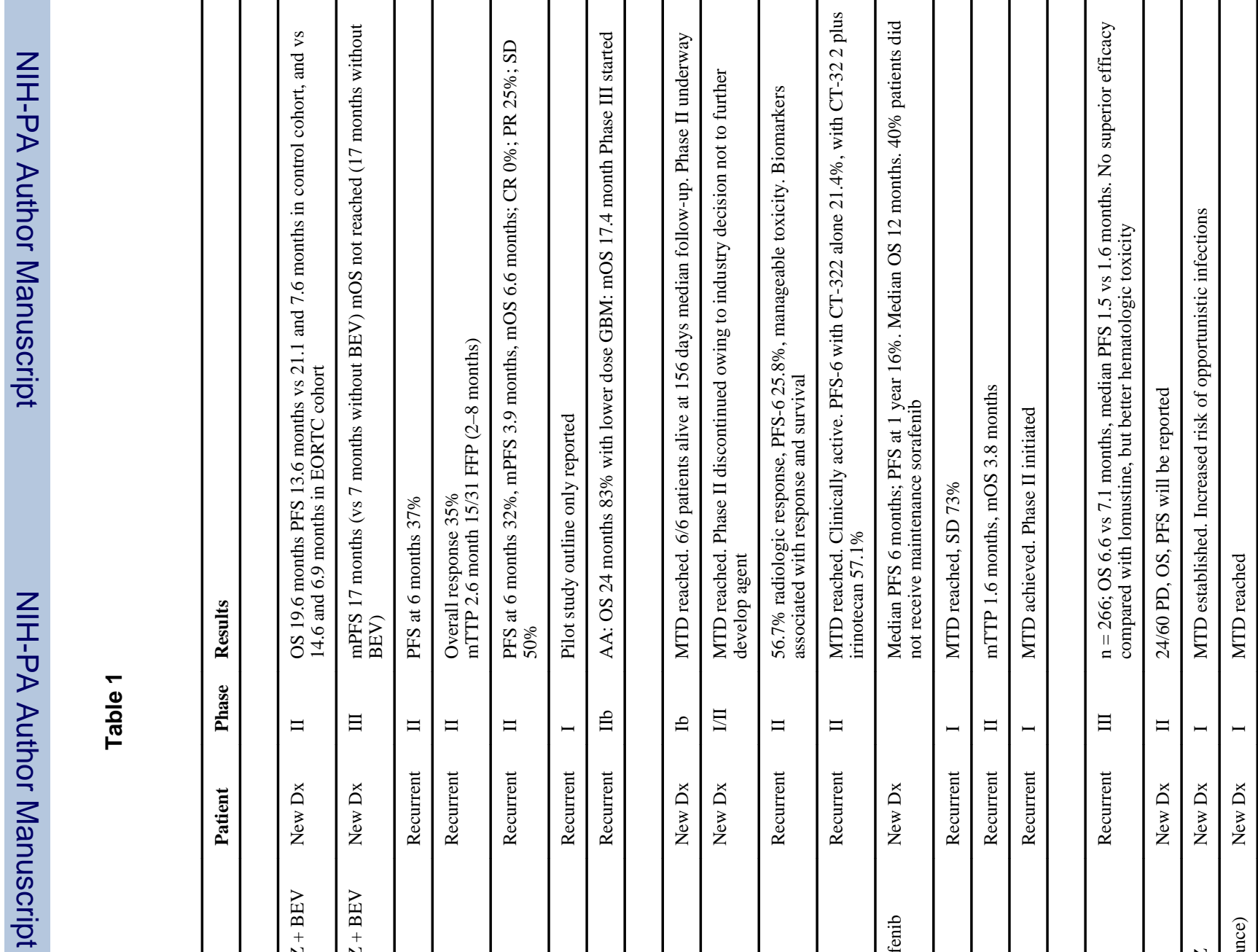

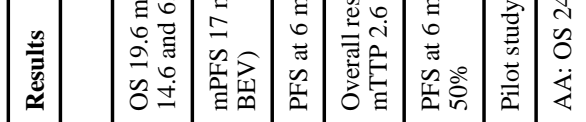

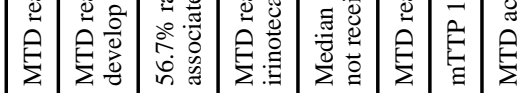

$=0 \underset{\mathrm{N}}{\mathrm{N}} \Sigma$

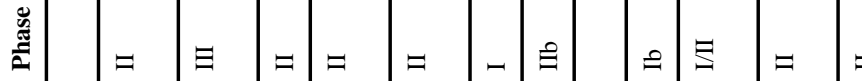

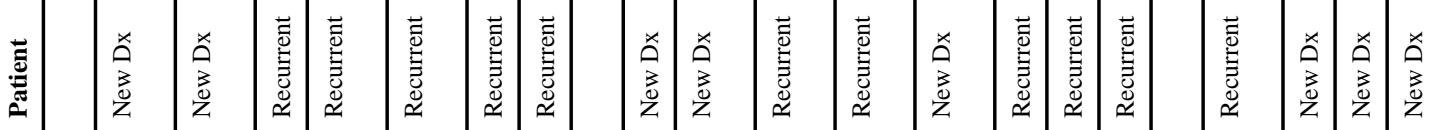

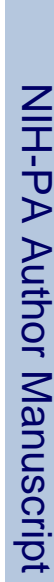
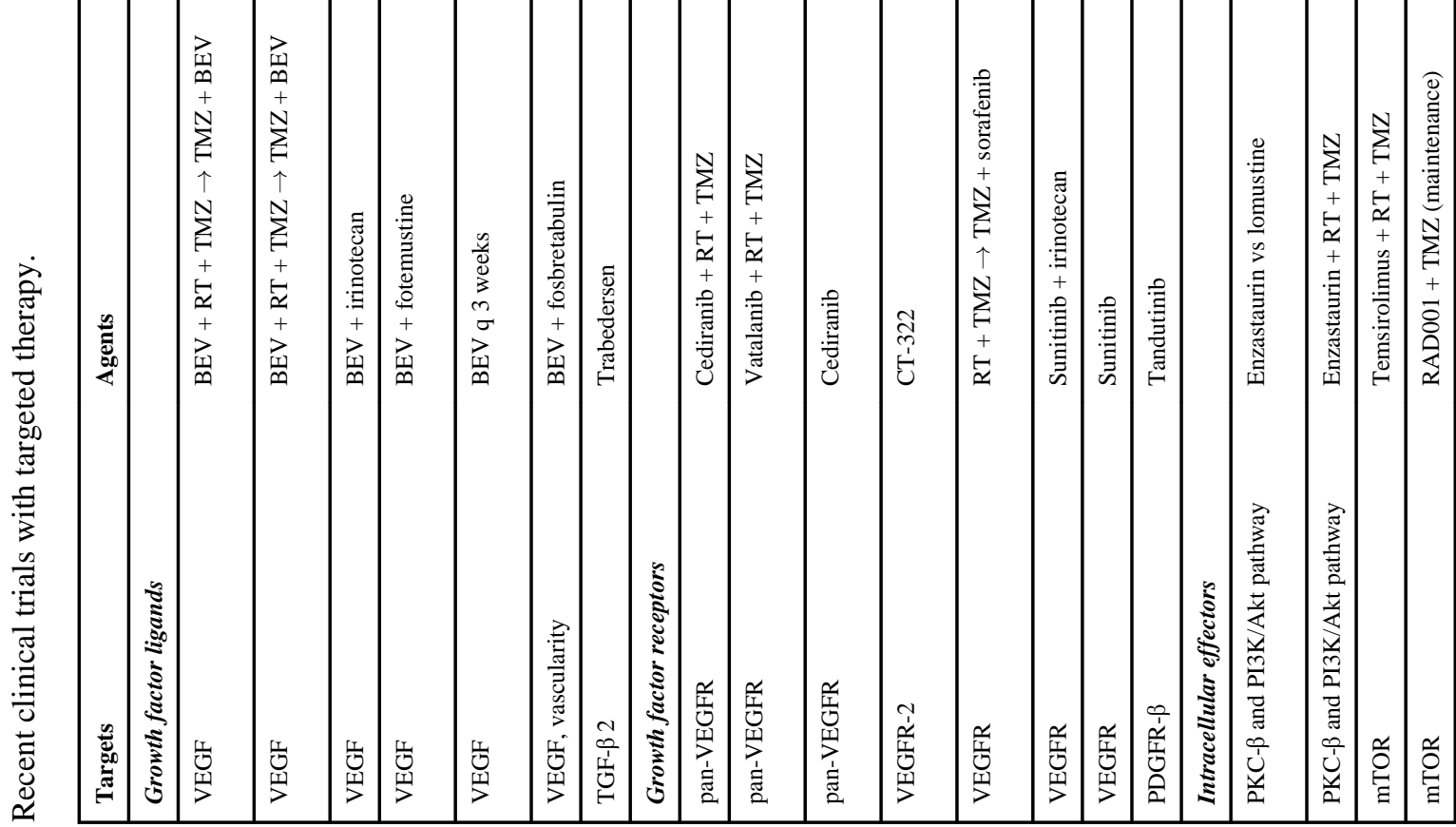


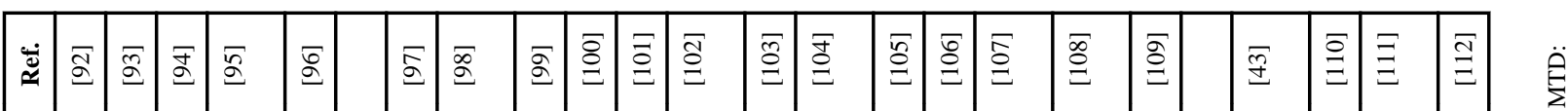

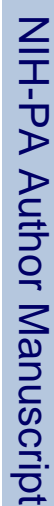

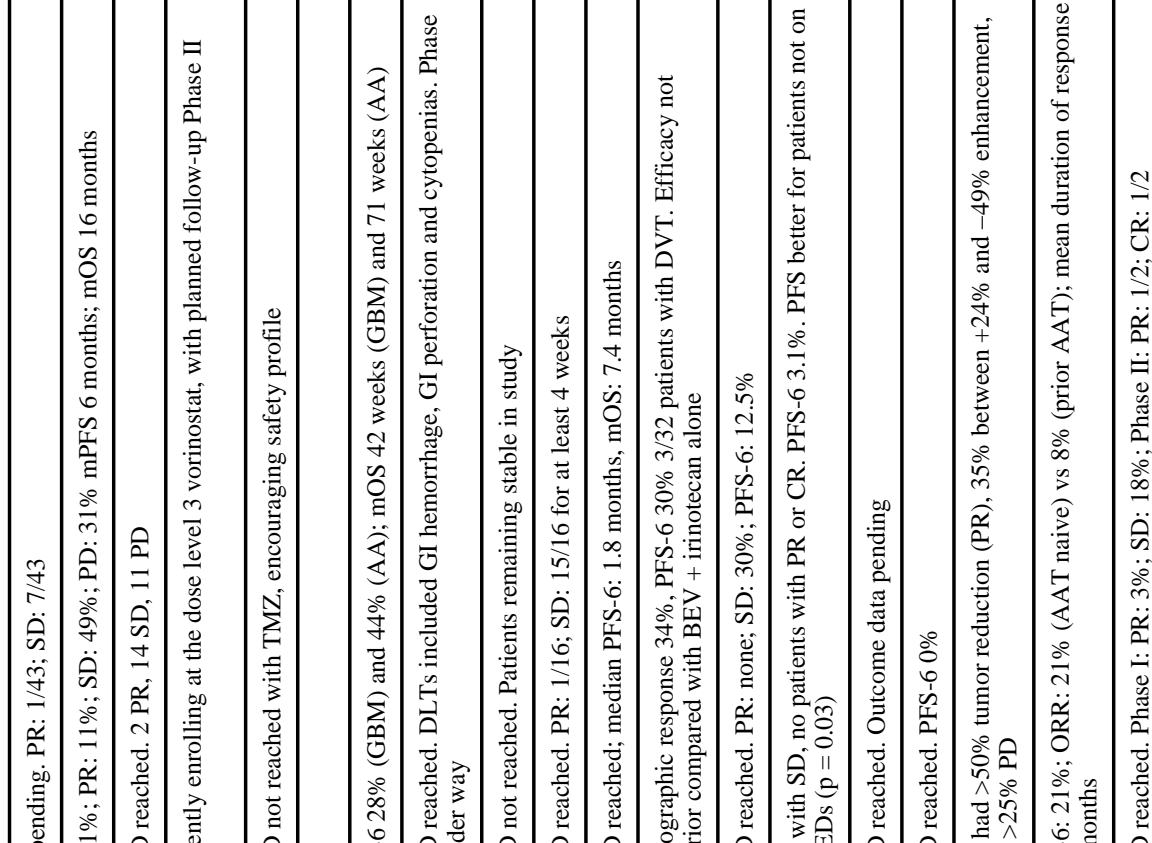

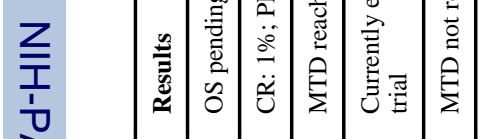
䆓

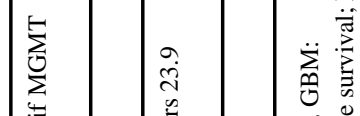

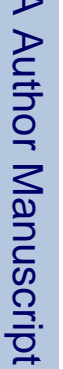

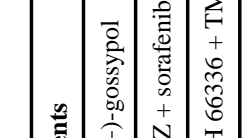
$=--$ $=--5=\Xi \equiv \equiv=5$

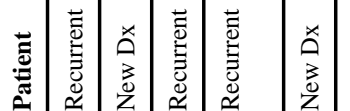

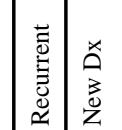

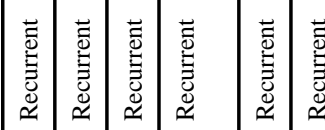

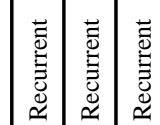

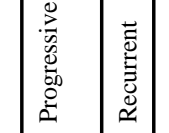

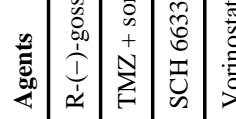
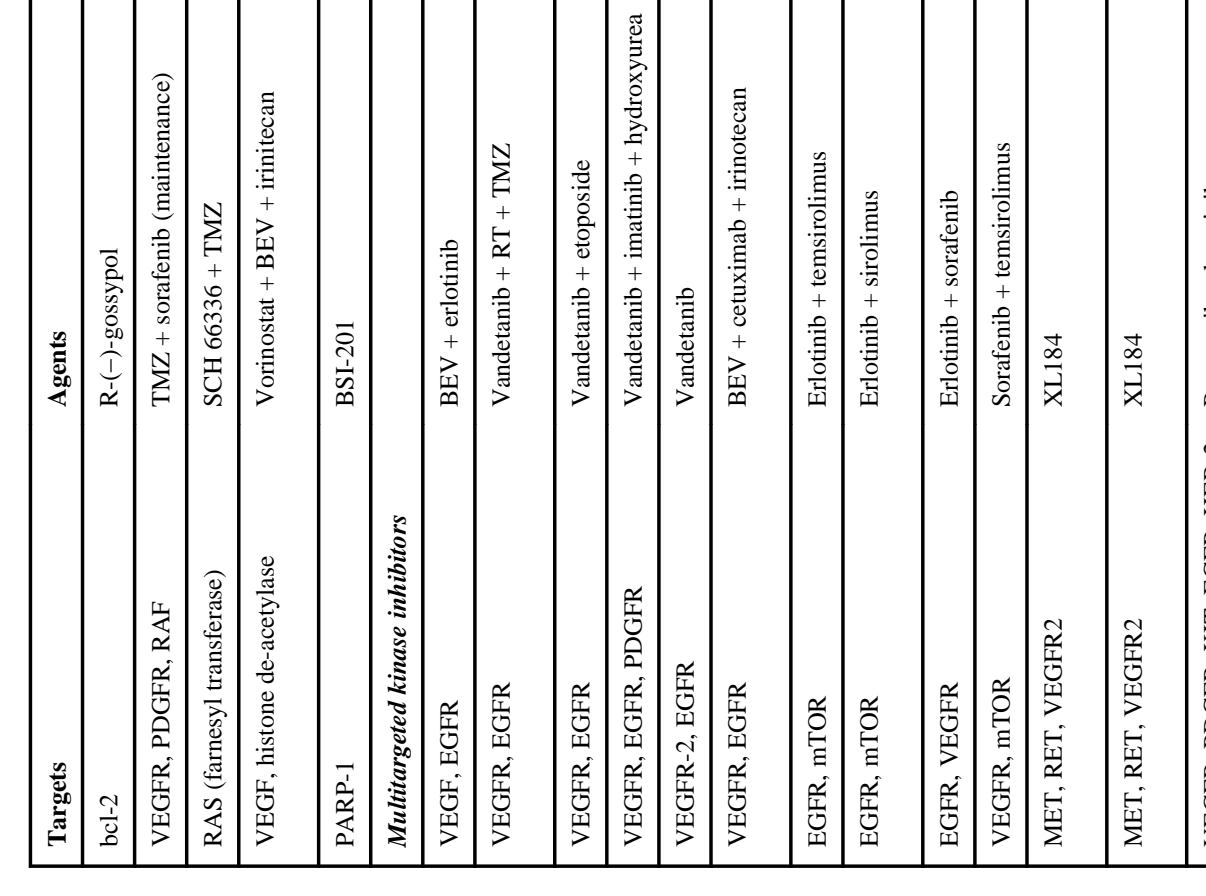
